Article

\title{
Investigating the Impact of COVID-19 Disruption on the Decarbonisation Agenda at Airports: Grounded or Ready for Take-Off?
}

\author{
Peter Hemmings ${ }^{1,2, *(D)}$, Michael Mulheron ${ }^{3}\left(\mathbb{D}\right.$, Richard J. Murphy $^{1}(\mathbb{D})$ and Matt Prescott ${ }^{2}$ \\ 1 Centre for Environment and Sustainability, University of Surrey, Guildford GU2 7XH, UK; \\ rj.murphy@surrey.ac.uk \\ 2 Carbon Strategy Team, Heathrow Airport Ltd., Hounslow TW6 2GW, UK; matt.prescott@heathrow.com \\ 3 Department of Civil and Environmental Engineering, University of Surrey, Guildford GU2 7XH, UK; \\ m.mulheron@surrey.ac.uk \\ * Correspondence: p.hemmings@surrey.ac.uk
}

\section{check for} updates

Citation: Hemmings, P.; Mulheron, M.; Murphy, R.J.; Prescott, M. Investigating the Impact of COVID-19 Disruption on the Decarbonisation Agenda at Airports: Grounded or Ready for Take-Off?. Sustainability 2021, 13, 12235. https://doi.org/10.3390/su132112235

Academic Editors: Baojie He, Ayyoob Sharifi, Chi Feng and Jun Yang

Received: 30 September 2021

Accepted: 3 November 2021

Published: 5 November 2021

Publisher's Note: MDPI stays neutral with regard to jurisdictional claims in published maps and institutional affiliations.

Copyright: (c) 2021 by the authors. Licensee MDPI, Basel, Switzerland. This article is an open access article distributed under the terms and conditions of the Creative Commons Attribution (CC BY) license (https:// creativecommons.org/licenses/by/ $4.0 /)$.

\begin{abstract}
COVID-19 has had wide-ranging impacts on organisations with the potential to disrupt efforts to decarbonise their operations. To understand how COVID-19 has affected the climate change mitigation strategies of Airport Operators (AOs), questionnaires and semi-structured interviews with Sustainability Managers were undertaken in late 2020 amidst a period of disruption. While all reported that COVID-19 impacted delivery of interventions and projects to mitigate climate change, the majority stated that it would not impact their long-term climate goals, such as Net Zero by 2050. The most popular climate change mitigation interventions AOs intend to deploy between now and 2030 are on-site renewables and Electric Vehicles and related infrastructure. Engineered carbon removal interventions were considered highly unlikely to be deployed in this timeframe, with potential implications for Net Zero decarbonisation pathways. Despite the severe impacts of COVID19 on the sector, results indicate that AOs remain committed to decarbonisation, with climate change action remaining the key priority for airports. Given ongoing financial and resource constraints, AOs will need to explore new business models and partnerships and nurture collaborative approaches with other aviation stakeholders to not only maintain progress toward Net Zero but "build back better". Government support will also be needed to stimulate the development of a sustainable, resilient, low-carbon aviation system.
\end{abstract}

Keywords: airport operators; COVID-19; climate change; sustainability; climate change mitigation

\section{Introduction}

The SARS-CoV-2 (COVID-19) pandemic has been, and continues to be, highly disruptive for the aviation industry. Border closures, travel restrictions and quarantine measures imposed by governments to prevent transmission of the virus and new variants have significantly reduced air traffic movements and passenger numbers. For airports, the reduction in air traffic movements, passengers and retail tenants has significantly impacted principal revenue streams. Compared to a business-as-usual (BAU) scenario, the global impact of COVID-19 in 2020 has been estimated to represent a reduction of up to 2.9 billion passengers and a loss of operating revenue for airlines of approximately USD 391 billion gross [1]. For airports globally, estimates suggest a 64\% loss in passenger traffic during 2020 and an associated USD 112 billion in airport revenues compared to a BAU scenario (Ibid.).

Airport Operator $(\mathrm{AO})$ organisations are adapting their future strategies to respond to two significant global pressures simultaneously: the COVID-19 pandemic, and climate change. To address the latter, airports must transition to a sustainable, zero-carbon air transport system that minimises the industry's environmental impact. Principally, this will require the systemic reduction and removal of greenhouse gas (GHG) emissions in 
line with the Paris Agreement, through the implementation of appropriate interventions. However, such interventions come at a financial and resource cost and AOs must now address the twin challenges of both the pandemic and climate change with significantly reduced access to capital, whilst also optimising ongoing operations. They must also balance social impacts such as job losses and associated future skill shortages if they are to maintain the expertise to deliver the required changes and protect growth.

It might be assumed that the organisational disruption and reduced revenues associated with the COVID-19 pandemic would mean that climate change mitigation and sustainability interventions will be delayed or cancelled, and the underpinning strategies reviewed and altered. However, aviation organisations continue to make long-term decarbonisation commitments [2] and phrases such as "build back better" are prominent in the lexicon of business leaders, tying a recovery of the sector to notions of sustainability and "greening" [3].

The impact of COVID-19 on the decarbonisation agenda at airports remains to be addressed in the literature to date (see Supplementary Materials File S1 for the literature review conducted as part of this study).

With the above in mind, this research sought insight on key emerging themes on: how COVID-19 may have impacted climate change mitigation strategies at airports and any low-carbon, or carbon-saving, opportunities resulting from changes to the existing regime at airports. Consideration was also given to analysing what influence the COVID19 pandemic may have on the decarbonisation transition of airports seeking to reach “Net-Zero" by 2050.

The research was conducted via analysis of the responses to an online, self-completion questionnaire with follow-up by semi-structured interviews with a range of Sustainability Managers at AOs in Europe and North America. This was used to assess the impacts of the COVID-19 pandemic on airport climate change mitigation efforts during the emergence of the "second wave" of the pandemic (from October 2020 [4]). Recommendations on how impacts of the pandemic on the climate change agenda of airports and aviation can be alleviated are given based on the research findings.

\section{Materials and Methods}

A multi-case study approach is adopted to identify high-level emerging themes on the impacts of COVID-19 on airports. The research techniques employed include an online self-completion questionnaire and follow-up semi-structured interviews with selected respondents, to explore emerging topics in further detail. Figure 1 shows the study design.

Population and Sampling-The targeted population for the questionnaire were Heads of Environment and Sustainability at AOs. This group was deemed most familiar with the climate change and sustainability strategy at their respective organisations. A limitation is recognised in exempting operational staff who could be more cognizant of potential low-carbon opportunities arising during this period.

Sixty contacts at AOs in Europe (85\%), North America (10\%) and the Asia-Pacific region $(5 \%)$ representing both operators of single airports and multiple airports were invited to participate as respondents to the questionnaire. The invitees were selected based on their interest or expertise in environmental issues at airports or were suggested on a similar basis by other participants.

The researchers acknowledge that the small sample size cannot be assumed to be fully representative of the whole population of AOs. The responses received represent a substantial sample of approximately $60 \%$ as a proportion of passengers carried in Europe in the year prior to the COVID-19 pandemic. Overall, the sample achieved was considered suitable for a "snapshot study" to identify the key themes during the second wave of COVID-19. Adopting a multi-case study approach that seeks to identify themes common across all cases means that some level of generalisation can be applied. The limitations of the opportunistic sampling undertaken must also be recognised; however, it was deemed suitable to achieve the aims of the study and allowed for a high response rate to the questionnaire. 
Ethical approval to undertake the research was gained through the research institution's ethics self-assessment process.

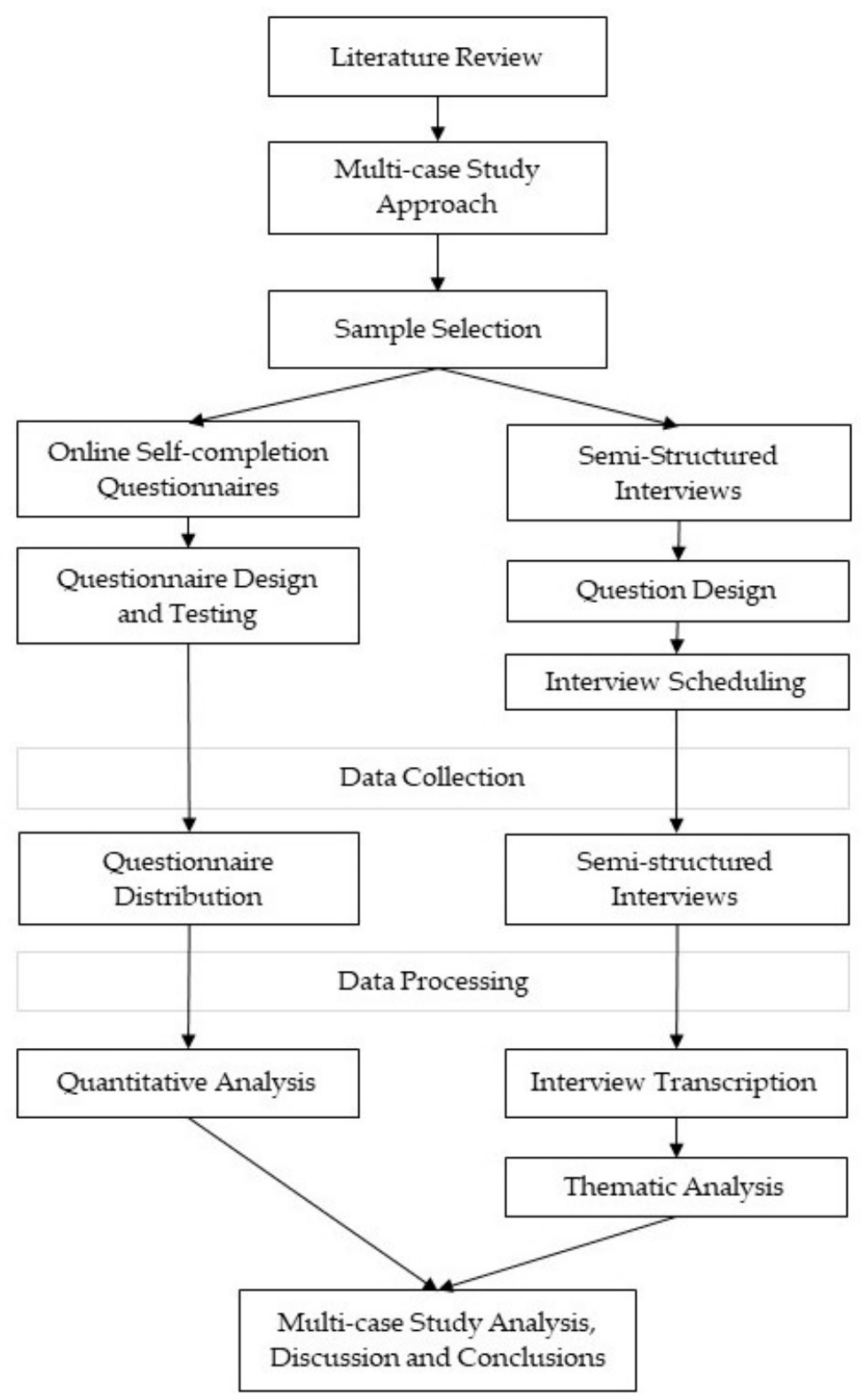

Figure 1. Study design.

Questionnaire Design and Distribution-The questionnaire was constructed and hosted on the QualtricsXM platform. The landing page gave an overview of the research, participation requirements including anonymity, and was followed by a consent form. The design, flow and functionality were tested within the research team prior to launch. The questionnaire comprised four questions on basic respondent information, followed by five questions on Strategy and Interventions, and six questions on COVID-19 Impact.

Strategy and Intervention Questions-These addressed which interventions AOs intend to deploy, when they intend to deploy them, and their intended funding sources. This was requested to form an understanding of the respondents' current and future plans in relation to barriers, opportunities and potential long-term goals. Details were sought on the following two questions to enable the analysis in Section 4:

1. Planned Interventions: Respondents were presented with a list of $22 \mathrm{GHG}$ emission reduction and removal interventions compiled by the authors and considered broadly 
representative of those that are technologically feasible for implementation at airports now or within the next three decades (Table 1). These range from policy advocacy to technological solutions; some are on-site solutions and some market-based. Based on their own implementation plans, the respondents were asked to group these into four categories based on their own implementation plans: (1) 2020 to 2030; (2) 2030 Onward; (3) "We already do this"; (4) "We don't intend to pursue this".

2. Funding: Respondents were asked "Please indicate how you intend to fund these interventions", and to distribute the (hypothetical) funding across the following three categories: (1) Internal funding; (2) External funding-Research and Innovation Grants; (3) External funding-Industrial partnerships, Other Funding Models.

Table 1. Intervention list presented in AO questionnaire. An indication is given as to which emission scopes (in line with the GHG Protocol [5]) the intervention will impact, and by what means. Reduction denotes an intervention that will reduce overall emissions compared to a business-as-usual state through reducing or avoiding fuel use. Removal denotes an intervention that will sequester carbon dioxide. LTO: Landing and Take-Off. vTOL: Vertical Take-off and Landing. HVO: Hydrotreated Vegetable Oils. BECCS: Bioenergy Carbon Capture and Storage. DACCS: Direct Air Carbon Capture and Storage.

\begin{tabular}{|c|c|c|c|}
\hline No. & Intervention Description & Scopes Impacted & $\begin{array}{c}\text { Emission Reduction } \\
\text { or Removal }\end{array}$ \\
\hline 1 & $\begin{array}{c}\text { Decarbonising Airport } \\
\text { Infrastructure and Heating }\end{array}$ & 1 & Reduction \\
\hline 2 & $\begin{array}{l}\text { On-site Renewable Electricity } \\
\text { Generation }\end{array}$ & 2 & Reduction \\
\hline 3 & $\begin{array}{c}\text { Purchasing Renewable } \\
\text { electricity (Market based } \\
\text { instruments) }\end{array}$ & 2 & Reduction \\
\hline 4 & $\begin{array}{c}\text { Decarbonising Colleague } \\
\text { Surface Access, e.g., car share } \\
\text { schemes }\end{array}$ & 3 & Reduction \\
\hline 5 & $\begin{array}{l}\text { Decarbonising Passenger } \\
\text { Surface Access, e.g., access } \\
\text { charges, new public } \\
\text { transport options }\end{array}$ & 3 & Reduction \\
\hline 6 & $\begin{array}{c}\text { Utilising low carbon } \\
\text { construction materials and } \\
\text { processes }\end{array}$ & 3 & Reduction \\
\hline 7 & $\begin{array}{l}\text { Pursuing Circular Economy, } \\
\text { waste re-use and } \\
\text { servicisation opportunities }\end{array}$ & 3 & Reduction \\
\hline 8 & $\begin{array}{l}\text { Policy Change Advocacy } \\
\text { (National, International) }\end{array}$ & 3 & Reduction \\
\hline 9 & $\begin{array}{c}\text { Tackling fugitive emission } \\
\text { sources, e.g., De-Icer and Fire } \\
\text { Training }\end{array}$ & 3 & Reduction \\
\hline
\end{tabular}


Table 1. Cont.

\begin{tabular}{|c|c|c|c|}
\hline No. & Intervention Description & Scopes Impacted & $\begin{array}{c}\text { Emission Reduction } \\
\text { or Removal }\end{array}$ \\
\hline 10 & $\begin{array}{l}\text { Provision of Fixed Electric } \\
\text { Ground Power (FEGP) }\end{array}$ & 3 & Reduction \\
\hline 11 & $\begin{array}{c}\text { Enabling Sustainable } \\
\text { Aviation Fuel (SAF) up-take } \\
\text { at airport }\end{array}$ & 3 & Reduction \\
\hline 12 & $\begin{array}{c}\text { Provision of Pre-Conditioned } \\
\text { Air (PCA) }\end{array}$ & 3 & Reduction \\
\hline 13 & $\begin{array}{c}\text { Tackling LTO emissions, e.g., } \\
\text { E-taxiing, Single Engine } \\
\text { Taxiing }\end{array}$ & 3 & Reduction \\
\hline 14 & $\begin{array}{c}\text { Infrastructure provision for } \\
\text { future aircraft types, e.g., } \\
\text { electric, hybrid, hydrogen, } \\
\text { vTOL }\end{array}$ & 3 & Reduction \\
\hline 15 & $\begin{array}{l}\text { Enabling or influencing } \\
\text { airspace improvements }\end{array}$ & 3 & Reduction \\
\hline 16 & $\begin{array}{l}\text { Enabling or influencing } \\
\text { airfield and ground } \\
\text { movements improvements }\end{array}$ & 3 & Reduction \\
\hline 17 & $\begin{array}{l}\text { Establish a Voluntary Carbon } \\
\text { Offsetting Platform }\end{array}$ & 3 & Reduction/Removal \\
\hline 18 & $\begin{array}{l}\text { Provision of Electric Vehicles } \\
\text { and Charging Infrastructure }\end{array}$ & 1,3 & Reduction \\
\hline 19 & $\begin{array}{c}\text { Alternative fuels for ground } \\
\text { vehicles, e.g., HVO, } \\
\text { Hydrogen }\end{array}$ & 1,3 & Reduction \\
\hline 20 & $\begin{array}{l}\text { Pursuing Carbon Capture } \\
\text { and Utilisation technologies }\end{array}$ & $1,2,3$ & Removal \\
\hline 21 & $\begin{array}{c}\text { Pursuing Engineered Carbon } \\
\text { Removals, e.g., BECCS, } \\
\text { DACCS }\end{array}$ & $1,2,3$ & Removal \\
\hline 22 & $\begin{array}{l}\text { Pursuing Removals through } \\
\text { Nature Based Solutions, e.g., } \\
\text { Afforestation, Reforestation }\end{array}$ & $1,2,3$ & Removal \\
\hline
\end{tabular}

COVID-19 Impact Questions-First, respondents were asked five questions in relation to the impact of COVID-19 on their implementation plans for climate change interventions and the perceived threat to the organisation of both external pressures. Respondents were asked to give the extent to which they agreed with the following statements on a 7-point Likert scale:

1. "The impacts of COVID have made climate change a higher priority within the business"

2. "COVID is an existential threat to our business"

3. "Climate Change is an existential threat to our business"

4. "The highest priority for the organization is business continuity"

5. "The impacts of COVID have disrupted our ability to implement planned carbon reduction and removal strategies"

Finally, they were asked to record in "free text" responses: (i) any notable low-carbon opportunities and barriers to mitigation efforts resulting from the pandemic, and (ii) asked to give their perception of longevity of the opportunities. 
Questionnaire Distribution-Emails containing a link to the online survey and project overview were sent to the 60 contacts identified. No incentives were offered for completing the questionnaire. Reminder emails to encourage participation were sent to those who did not engage initially. The questionnaire ran for 42 days, from 7 October 2020 to 19 November 2020; this period was representative of a widely accepted "second wave" of confirmed COVID-19 cases within the United Kingdom (UK), Europe and North America and was prior to major announcements regarding vaccines and immunisation plans. Questionnaire responses were included for analysis at a completion rate of $40 \%$ or above, reflecting consent given and a minimum of one question answered.

Semi-structured Interviews-Semi-structured interviews were used to expand on key themes emerging from the questionnaire responses. Nine interview participants from nine different $\mathrm{AOs}$ were identified from questionnaire respondents who had indicated their interest in interview participation or were approached by the research team. Anonymity was offered, with any identifying information about the participant and their organisation removed. Interviews were conducted online, recorded, and transcribed.

Interviews were approximately $30 \mathrm{~min}$ in length, with questions focusing on four high-level topics:

1. Opinion on the current standing of climate change and sustainability agenda within the business given COVID-19 disruption: what has changed; do they recognise the recent narrative around sustainable or green recovery.

2. Potential Opportunities: do they recognise any changes in operation or working at the airport that might unlock carbon reductions or a more sustainable way of operating into the future; the perceived longevity of these opportunities.

3. Barriers: respondents were asked to identify both short-term barriers to implementation of projects, and long-term impact in regard to their climate change or sustainability targets (for many "Net Zero" by 2050 targets); the perceived longevity of these; whether some COVID-19 mitigation strategies are counter to climate change mitigation and sustainability measures; what might provide resilience to similar events in the future. Any high-level opportunities and barriers participants identified previously in the questionnaire were explored in further detail.

4. Strategy: Participants were asked to provide an overview of how their climate change mitigation strategy is set and to identify the main drivers.

Thematic analysis of the interview response transcripts was undertaken using NVivo 12 Pro using the Template Analysis approach [6,7]. This was selected as a flexible approach and allowed for the use of a priori codes followed by an iterative, inductive approach, refining the framework at stages of the data analysis. Three high-level a priori nodes were determined based on the study aims (see Table 2). The framework was refined for every two transcripts coded, with redundant codes being removed and appropriate clustering of codes, the framework subsequently being reapplied to the data. No inter-coder analysis was used. 
Table 2. Name and description of a priori codes.

\begin{tabular}{|c|c|c|}
\hline Level 1 & Level 2 & Description of Node \\
\hline Impact & $\begin{array}{c}\text { Barriers to } \\
\text { implementation } \\
\text { Long-term goal impacts } \\
\text { Operational impacts }\end{array}$ & $\begin{array}{l}\text { New and emerging COVID-related barriers to } \\
\text { the implementation of climate change } \\
\text { mitigation strategies by Airport Operators. } \\
\text { Airport Operators' perceived impact of COVID } \\
\text { on their long-term climate change mitigation } \\
\text { objectives and goals. } \\
\text { Any unexpected, new or emerging } \\
\text { COVID-related impacts on airport or related } \\
\text { operations that have a consequence on the } \\
\text { climate change mitigation and wider } \\
\text { sustainability agenda at airports. }\end{array}$ \\
\hline Opportunities & & $\begin{array}{l}\text { Any emerging or new opportunities that } \\
\text { Airport Operators have identified in this } \\
\text { period as supportive to the climate change } \\
\text { mitigation or wider sustainability agenda at } \\
\text { airports. }\end{array}$ \\
\hline Strategy & & $\begin{array}{l}\text { The perceived strategic importance of the } \\
\text { climate change mitigation agenda at airports } \\
\text { following COVID and reasons for this, } \\
\text { including internal and external drivers. }\end{array}$ \\
\hline
\end{tabular}

\section{Results}

The results are presented in two separate sections: Section 3.1 for the responses to the online questionnaire, and Section 3.2 on the views of the interview participants.

\subsection{Online Self-Completion Questionnaire}

Twenty-two Airport Operators responded to the questionnaire, representing a 37\% response rate. On average, respondents completed $92 \%$ of the questionnaire. The location and characteristics of the respondents are given in Table 3 (categorised for anonymity). The respondents represent a range of organisation sizes (indicated by pre-COVID passenger numbers [8,9], and revenue (organisations' 2019 Annual Report where publicly available)). The sample is mainly composed of European airport operators (82\%), reflective of the European focus in the targeted sample. As noted above, although statistical generalisation is not possible given the sample size, the results can be considered meaningful, particularly for Europe, given that the AOs responding to the study represented the majority (60\%) of pre-COVID-19 European passenger numbers (2019).

Planned Interventions: (detailed data are given in Supplementary Materials File S2, Figure S1a-d). In the 2020-2030 period, AOs intend to implement $66 \%$ (164) of their total intended interventions. This decade sees a focus on mitigating direct emissions with a strong focus on on-site renewables, but also an intent to explore Scope 3 emission reduction around surface access and electric vehicles (EVs), low carbon construction and enabling Sustainable Aviation Fuel (SAF).

The year 2030 onwards sees an intention to focus on supporting alternative propulsion and alternative fuels, the top 3 selected interventions for this category being: infrastructure for future aircraft types, carbon capture and utilisation technologies, and alternative fuels for ground vehicles.

AOs reported having already taken positive steps towards tackling Scope 2 emissions with $71 \%(n=21)$ already reporting they are purchasing renewable energy. They also reported progress on enabling Scope 3 emissions reductions, particularly within aircraft at stand and LTO: $65 \%(n=20)$ already provide FEGP, $58 \%(n=20)$ provide PCA, and $60 \%(n=20)$ report enabling airspace improvements. 
Table 3. Characteristics of the AOs responding to the questionnaire.

\begin{tabular}{cc}
\hline AO Location & Respondents per location \\
\hline Europe & 18 \\
North America & 3 \\
Asia and Pacific & 1 \\
\hline Total Passenger numbers 2019 & Respondents per category \\
\hline$<5$ million & 3 \\
5 to 10 million & 5 \\
10 to 20 million & 4 \\
20 to 50 million & 4 \\
50 to 80 million & 3 \\
$>80$ million & Respondents per category \\
\hline Operating Revenue 2019 (GBP equivalent) & 3 \\
\hline 100 million & 4 \\
100 to 500 million & 6 \\
1 million to 1 billion & 4 \\
$>2$ billion & 1 \\
\hline
\end{tabular}

Removal interventions scored highest as those that AOs do not intend to deploy; a particular intention to avoid engineered carbon removals such as DACCS is identified.

Funding: Figure 2 shows a clear intention on the part of AOs to rely primarily on internal funding sources to implement their chosen interventions. Comparison of intended funding sources against pre-COVID passenger numbers and revenue (as an approximate indicator of size of organisation) shows no correlation with the intent to seek external funding (Pearson's $r 0.04$ and $r 0.08$, respectively). This refutes the hypothesis that AOs with larger (pre-COVID) revenues are more likely to fund interventions with internal capital. Additionally, the multiple benefits of exploring external funding seem desirable irrespective of organisation size or revenue.

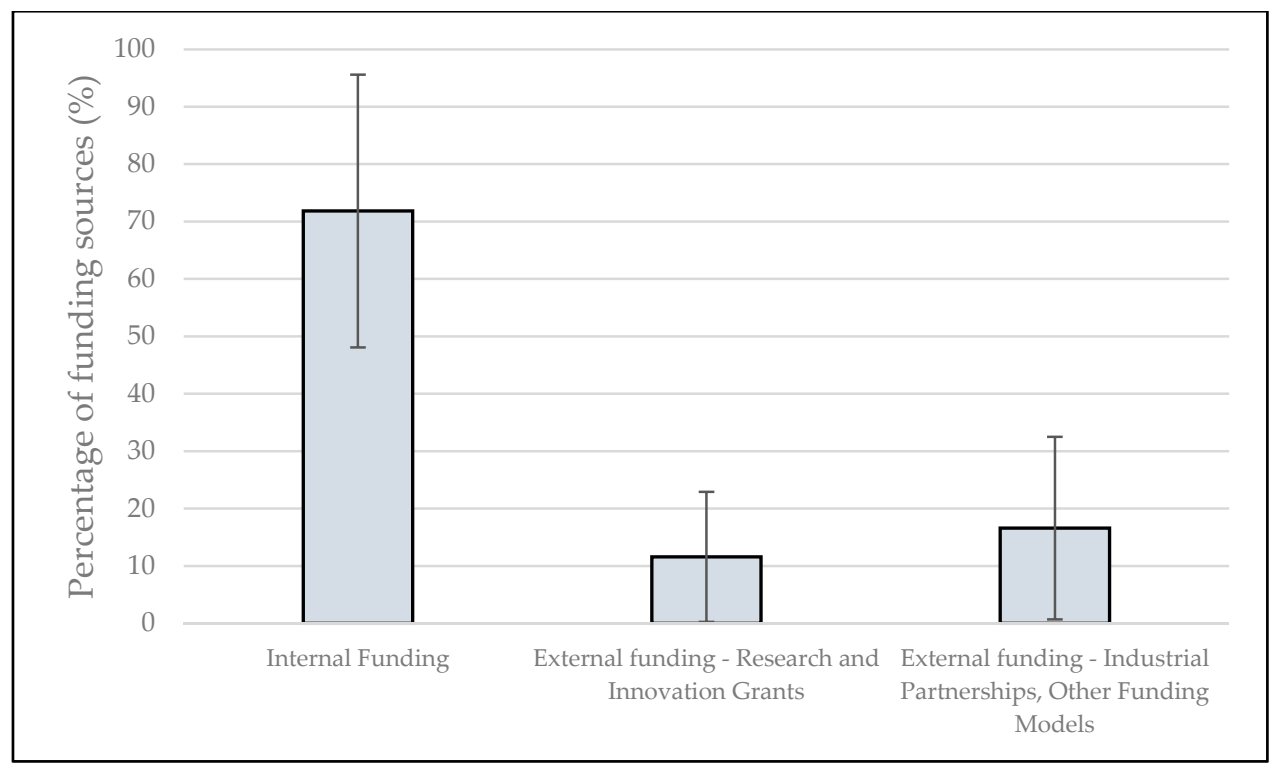

Figure 2. AO responses for intended funding sources.

Perception of risk: Fifteen $(n=19)$ AOs strongly agreed or agreed with the statement that COVID-19 is an existential threat to their business (Figure 3). Attitudes to the same statement but regarding climate change were noticeably less strong but AOs were still in agreement, with nine $(n=19)$ noting "Agree". When asked if the impacts of COVID-19 had 
made climate change a higher priority within the business, respondents held divergent views and six recorded "neither agree nor disagree".

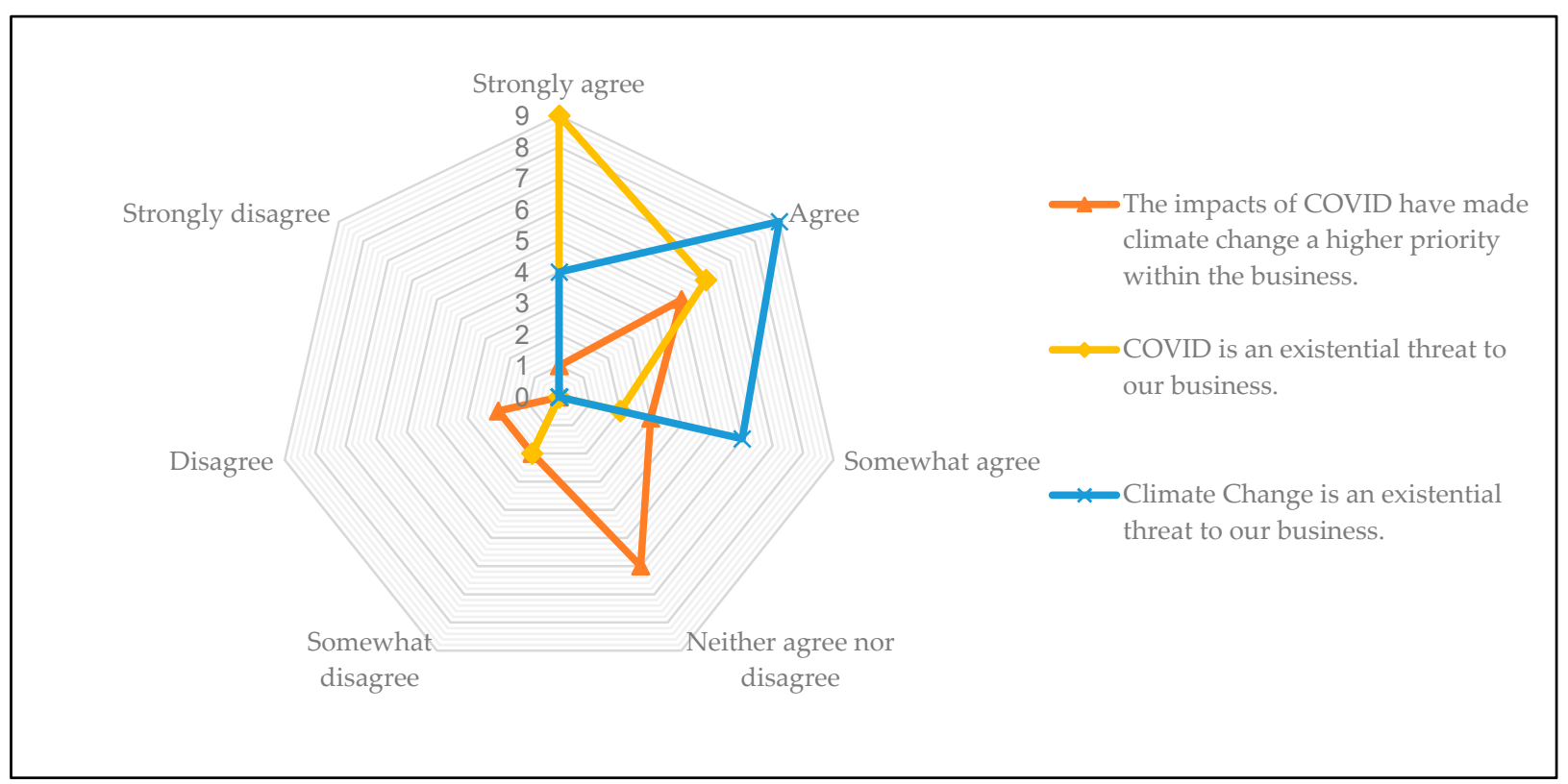

Figure 3. Business risk perceived by AOs from COVID-19 and climate change and the priority of climate change within the business.

Respondents held convergent views with regard to the statement "the highest priority for the organisation is business continuity", with seventeen $(n=19)$ recording "strongly agree" or "agree" (Figure 4). AOs were also largely in agreement with the statement that COVID-19 had led to the disruption of intervention implementation, with eight $(n=19)$ stating "somewhat agree"; however, there was some deviation, with one respondent strongly disagreeing.

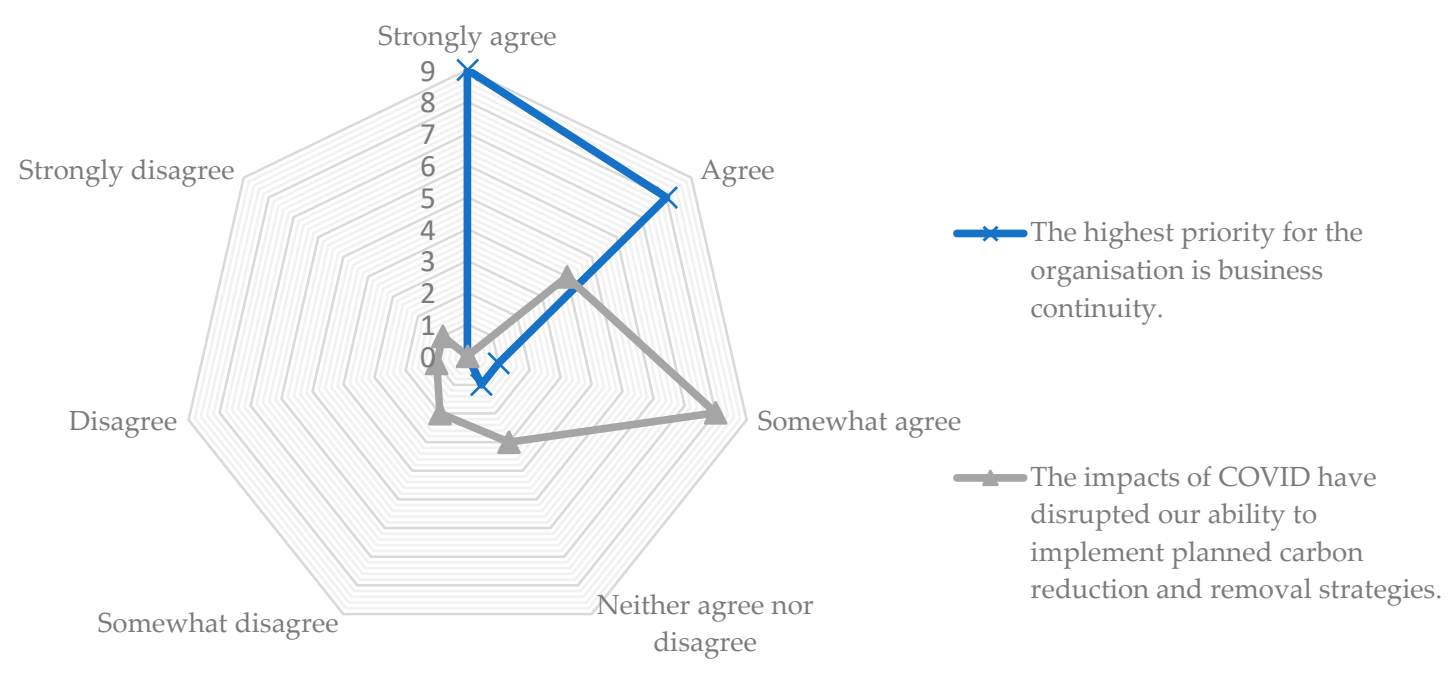

Figure 4. AO attitudes on business continuity and disruption to climate change mitigation strategies.

Opportunities and Barriers: Eleven $(n=19)$ respondents recognised potential lowcarbon, or emission saving, opportunities coming out of this period. Many raised tangible 
benefits for Scope 3 emissions reduction through reduced air traffic, surface access and energy consumption. However, themes also emerge around changes in practice, including a change in pace unlocking opportunities, methods of working, and a potential shift to digitalisation; see Supplementary Material File S2, Table 1 for supporting quotes from AOs on this aspect.

Fifteen $(n=19)$ AOs recognised barriers in this period to implementing their climate change mitigation interventions. All respondents agreed on lack of funding as a barrier to their implementation plans. Some alluded to this being a temporary or short-term disruption to current projects. Another emerging theme was lack of human resources, as was the focus on health and safety, resulting in a change in priority and its potential implications for waste and energy; see Supplementary Material File S2, Table S2 for supporting quotes from $\mathrm{AOs}$ on this aspect.

\subsection{Interviews}

The nine semi-structured interviews were conducted in October and November 2020 with Heads of Sustainability and Environment at AOs in the UK, Europe and North America, representing a range of organisation structures (single or multiple airport management) and sizes (based on total annual passengers in 2019; categorised for anonymity) (Table 4). Input from an $\mathrm{AO}$ with a large domestic market is given through the inclusion of North American participants. The sample predominantly represents European and UK AOs.

Table 4. Characteristics of Airport Operators interviewed (passenger numbers: $[8,9]$ ).

\begin{tabular}{ccc}
\hline Identifying Code & Location & Size (Passengers 2019) \\
\hline A1 & North America & 50 to 80 million \\
A2 & Europe & 5 to 10 million \\
A3 & Europe & 10 to 20 million \\
A4 & Europe & $>80$ million \\
A5 & UK & 10 to 20 million \\
A6 & North America & 50 to 80 million \\
A7 & UK & 5 to 10 million \\
A8 & UK & $>80$ million \\
A11 & Europe & 50 to 80 million
\end{tabular}

The thematic analysis results are summarised in Appendix A, Table A1. Four highlevel themes emerged: Impact, including barriers to intervention implementation and other notable sustainability impacts; Opportunities that support climate change mitigation or wider sustainability; Recovery, including perception of uncertainty and government intervention; and Strategy, including perceived drivers or agents influencing the climate change agenda at airports. Further detail and highlights of the interview participants' points are presented below, structured in relation to these four themes.

\subsubsection{Impacts}

Participants largely agreed that COVID-19 has caused significant short-term disruption to climate mitigation plans and projects-speaking of the need to "shift to the right" or "change the action plan". Views on long-term impacts were divergent: two-thirds of the participants felt COVID-19 would not impact achievement of long-term carbon reduction goals such as Net Zero by 2050. One European participant described these targets to be sufficiently distant that a recovery in the next 5 years would still allow these to be met. This was notably linked to confidence that COVID-secure travel would be enabled via medicine and/or politics. However, a third of participants were more guarded in their response, noting the potential for COVID-19 to cause long-term disruption to the aviation industry, and progress on the Net Zero agenda.

The main barrier to intervention implementation, identified by seven participants, was lack of available capital. The consequences of reduced revenue ranged from "having to 
re-justify some expenses", to reducing or suspending capital programmes, including climate change mitigation or sustainability projects. AOs expressed confidence in a recovery at some point and were keen to stress that financial barriers were temporary, causing delay but not termination of their plans. Stemming cash flow was reported as a challenge, given the need to maintain essential operations associated with safety, security and maintenance: "but there's all the costs". Some have been affected more than others, depending on the severity of travel restrictions (varying by jurisdiction), and international versus domestic market share at the airport. The strength of domestic market was reported as a factor allowing two AOs in North America to be in a more business-as-usual position than their European colleagues, one noting that large European airports "are in survival mode". Beyond financial barriers, five participants raised lack of human resources as a barrier to implementing climate change mitigation strategies.

AOs were asked to identify any new or emerging COVID-related impacts that may affect their climate change mitigation agenda. Four main areas were recognised: energy use, change in air traffic, operational vehicle use, and waste. In addition to these, participants noted the importance of ensuring Health and Safety as an obvious priority in this period, with one citing Maslow's Hierarchy of Needs and the basic requirement to provide safety and security for passengers. At most, any undesirable impacts on recent climate change and sustainability achievements in this period were seen as a slight frustration. Essentially, they were perceived as short-term disruptions of relatively low impact due to being largely offset by low traffic and passengers, and easy to mitigate should they persist: "If it does go on longer there is going to be various mitigations in place to compensate for it as much as we can". However, with one exception who noted undertaking communication with airport stakeholders on best practice around waste handling, no participants reported any measures currently in place to deal with these short-term issues.

Regarding AO energy use and Scope 1 and 2 emissions, it was noted that maximising fresh air intake and optimising heating and ventilation systems for COVID-19 were problematic. One AO recognised that this would likely cause the use of more gas in winter for terminals not yet running on renewables. The same AO spoke of the importance of indoor air quality and ventilation being part of a larger, healthy-buildings piece that needed attention within the sector: "we really need to have a way to improve the ventilation of our spaces to make them healthier for the occupants". One European AO gave the example of not seeing an expected proportionate decrease in energy consumption in line with reduced operations, triggering analysis into the source of this disparity. Another UK airport echoed having been able to undertake a forensic approach to reviewing building management systems: "It's made us be able to understand a bit more, "OK, well what are the biggest triggers in terms of energy use?"', adding that it is not every day one is able to switch off a terminal and interrogate its operation.

Many participants highlighted short-term impacts to air traffic and operations at the airport. Most recognised the significant reduction in air traffic as an obvious environmental benefit through avoided emissions, with one suggesting it would be likely to offer a net environmental benefit.

Two AOs offered examples of delayed climate change and environment projects. One spoke of plans to construct a new on-site plant. The same AO spoke of likely delays in the electrification of Ground Support Equipment (GSE) as they are more costly alternatives to Internal Combustion Engine (ICE) counterparts. The participants were confident that these projects had not been terminated but simply delayed pending removal of barriers and the return of revenue: "maybe in the alternate universe, where COVID didn't hit us, maybe we would be building this thing in a year or two", "we recognize we need to accelerate our climate action, not slow it down". One of them spoke to the role of the airport operator as an enabler of Scope 3 emissions reduction and delays in multi-stakeholder projects. On airline partners, they noted: "they're still onboard ... but it may get delayed just because they simply may not have the money to do it say in the next 2 years". 
Three AOs commented on the consequences of COVID-19 impact on efforts to mitigate emissions from passenger surface access and operational vehicles. One UK AO noted that one of their suppliers had adopted a "one passenger per vehicle" policy which "in some ways has kind of pushed things backwards". On passenger surface access, another observed a trend in public behaviour regarding concerns over the safety of public transport and a potential preference for private vehicle use-counter to the mode shift many airports have been working to influence. The emissions impact of both examples was perceived to be negligible when compared with the perceived net environmental benefits noted in other areas by participants, but it was nevertheless seen as a behaviour to track should it persist. Giving an example, one European AO noted a recent change to a national public transport incentive that, in response to the pandemic, had been amended to include some taxi and private hire vehicles. Uncertain of the longevity of this amendment, they believed that passenger surface access would likely return to its pre-COVID state: "as soon as the vaccine arrives and group immunity is acquired, I think the thing will return to what it was".

In terms of impact on embodied carbon, the topic of waste received the most attention from AOs. Three AOs noted disposable face masks and Personal Protective Equipment (PPE) as an emerging waste stream, one describing it as likely to be the next high-profile waste issue after a recent focus on plastics. The lack of clarity from the government on what constitutes "appropriate" PPE was given as a limitation by one UK AO not currently using reusable PPE at the airport. Poor availability and cost of reusables was given as another limitation to moving away from disposables. Two participants spoke of many waste issues being largely out of their direct control, often the result of individual policies of airlines and retail tenants. Their frustration was highlighted over having worked hard to introduce bespoke recycling facilities for problematic waste streams, for retail tenants to adopt "disposable only" and "no ceramics" policies in their response to COVID-19.

\subsubsection{Opportunities}

The main opportunities identified by participants were: alternative funding sources or business models; a time for collaboration; slower pace; and a time to reprioritise or reassess strategy.

Exploration of alternative funding and business models was a common opportunity theme. Driven by reduced capital programmes, AOs are exploring external funding opportunities to implement climate change and sustainability projects: "We're having to be more creative, so, we can't just rely on our capital funding because it's just not there". One European AO reported the intention to approach investors to fund and implement interventions with potential for the AO to buy-back in the future-a change to the typical asset ownership model. They gave two examples where this may be pursued: EV charging infrastructure and on-site renewable energy infrastructure. Similarly, a North American airport noted the method of continuing to work through COVID-19 to create a "shelf-ready" design and to explore grant funding opportunities to enable the construction phase. Three UK AOs also noted an intent to investigate or signalled that they had already spent time exploring partnership or green financing options across: energy efficiency; on-site and off-site renewable energy; and EV charging infrastructure. Such options were seen as a way of being able to continue to deliver on commitments made: "we might have to take some of our main commitments and try and bundle them up into something like that ... then we can still drive those ... basically a partnership agreement where the funding for this comes from the savings that are accumulated as part of a 20/25-year agreement". Two UK AOs recognized a shift in the organizations attitude to partnership models. One stated: "they didn't want to go into partnership agreements, and they wanted things to be with us. I suppose because it would be-these things are going to be quite long-term as well - and they obviously wanted to get the maximum benefit themselves, and whereas now, I think they're seeing that "oh actually, in order to do this, that is the only way that we are going to fund it", and so that is becoming much more attractive".

One European AO reported seeking common interests with providers looking to demonstrate decarbonisation technology on-site that could benefit both airport and airlines, 
using the example of a potential partnership with a sustainable fuel producer to utilise airport waste for fuel production - and thereby benefit the circular economy: "And if we can use also the waste that we produce in the airport that will be perfect-we will close the cycle".

However, uncertainties were raised around asset ownership, maintenance, and the feasibility of securing green funding, with one participant arguing that difficult conversations would have to be had between lenders and airports, with the latter having to prove the case for the certainty and benefits of a long-term investment in a time of significant uncertainty for the sector.

European Commission (EC) funding competitions for airports were looked on favourably by two European AOs, who proclaimed their intention to now pursue it: "I think this is the first time that at least our airports are facing that kind of possibility of funding". Another stated EC funding "is a good possibility to understand other airports' benchmark and to implement something at the airport, and we will get the funds back as well. So, it's a good possibility to solve and to move on with the sustainability initiatives".

Participants noted changes in working practices and attitudes resulting from the pressure on the organisation. Two UK AOs spoke of a new spirit of interdisciplinary collaboration within the organisation and airport stakeholders to find solutions, one hoping this would carry over in to climate change mitigation solutions and remove some pushback from stakeholders who previously did not consider the agenda a priority, or not fitting operationally: "I think that this is just showing that actually when we are faced with a problem, we can all come together and work and we can find solutions very quickly and change the way that we work quite quickly and put new things in place". Another noted: "to ask: can you find alternatives outside of just going to your shareholder and asking for a big capital budget? That, I would say, is as much as an opportunity as anything else because by doing that, it's making us, like a virtual team-with Engineering, Development, Ourselves, Finance - to think more holistically: what do we want out of this? How many things could we solve out of this? It's not just about reducing emissions it's also about improving resilience for the airport, being able to adapt to climate change as well".

Three AOs from Europe and North America attributed a slow-down in the pace of operations as beneficial in some context. One spoke of the rapid pace of capital development in the US prior to COVID-19 in an attempt to keep pace with the growth of the sector, renew aging infrastructure and under pressure from airlines to increase capacity-noting this made some sustainability professionals "very uncomfortable". They noted this slow-down had allowed for a testing and refining of the sustainability methodologies tied to capital projects: "By doing that, in this slow period, and testing things out, because that's really what we're doing right now, we're like, "Well, what if we did it this way? How much do we know at $30 \%$ design level that we can really impact here?". We're just learning a lot; I do think we can normalize that and have that continue into the future". In addition, one European AO noted that the slow-down was a means to more easily implement pilot projects where, previously, the pace of operations would have caused resistance to deployment. This was not reflected elsewhere, as stated earlier, with one UK AO noting that Operational departments were particularly stretched at this time.

\subsubsection{Strategy}

A general theme of reassessment and prioritisation of strategy and interventions emerged. For some, this involved a change in strategy toward preparation of concepts only, with a plan to seek external funding for implementation. Others intended to use available funding as efficiently as possible, leading to a prioritisation of interventions by carbon reduction potential: "I think what the squeeze on capital is partly doing is making us focus in a really laser-like way on: where can our investment deliver the most carbon reduction? And we've developed a Marginal Abatement Cost Curve model to look at the different investments we could make and help us prioritize, so we ensure that we are investing where the biggest reductions will happen".

Six AOs recognised that the climate change and sustainability agenda remained of strategic importance or had risen in importance in their organisation throughout 
the pandemic. Two posited that COVID-19 had been able to promote the climate change and sustainability agenda by demonstrating the significant impacts a realised external risk can cause to the sector. The point is that COVID-19, being a comparable risk in magnitude and severity to climate change, has allowed for a greater understanding of the risk posed by climate change to the organisation. Another participant, alluding to the next major global external risk being climate change, stated: "COVID has shown us what a genuine global crisis looks like. I mean, no one anticipated a year ago that a pandemic would bring the industry to its knees in the way it has globally — that has happened, and that's focused minds I think, because people have understood that ... If we think COVID's bad, climate has the potential to be significantly worse, so that's almost underlined the importance of action".

Other perceived drivers or agents influencing the current strategic priority of the climate change and sustainability agenda at airports were reported: its current standing, the consequence of several drivers and agents and not one alone. These are briefly presented below.

Several AOs noted increasing top-down support and pressure to take action on sustainability and climate change mitigation at airports, building over recent years but continuing through COVID-19: "I can tell you that right before COVID, so it's very recently, we have been facing huge pressure from our company in the environmental area. So right now, I can say that we are one of the most, not the most, but one of the most important things in the company, yes". Another noted that senior management buy-in to the climate change issue was a reason for COVID-19 being unlikely to prove detrimental to their long-term climate change goal: "No, I don't think so because I think the engagement of the management is there. And they have showed us that they care about this topic a lot. And they're willing to put money towards it when the money is available".

Two noted the influence of investors, one participant stating that they were now wise to social pressure groups, citing flygsham and Stay Grounded, which had bolstered the importance of taking action. Similarly, one reported being owned by an investment company whose investors were prioritising the issue: "it was really becoming a priority for them as well and their investors were starting to ask questions"; the AO described that this, along with COVID-19, had led to a mindset shift from the sustainability transition being an opportunity and a "nice-to-have", to something that now has to be done. One North American participant noted that their sustainability work had started to pay off in this respect, being of financial benefit to the business, as investors and rating agencies were wanting to see sustainability improvements at the airport: " ... we've been able to improve our credit ratings and the sale of bonds to support projects and investments in our airports. And the reason we've been able to get really good credit ratings and have really good rates on bonds, is because those investors and rating agencies are definitely giving value to airports that can show a reduction in carbon emissions in their sustainability or Environmental, Social and Governance (ESG) reports".

On organisational governance, one North American AO noted that the airport was overseen by an elected commission who, due to the politics and environmental consciousness of the electorate, had a strong environmental focus, favouring the implementation of interventions, including through COVID-19.

Public understanding of climate change and sustainability emerged as an influence, principally within the UK and Europe. Participants noted the rising pressure for climate action in aviation. In one isolated low-population European nation, public opinion was perceived to be more favourable due to understanding of the economic and social importance of the airport to the nation. Participants also noted public pressure was evident on other sustainability issues such as reduction in the use of plastics. Similarly, three AOs noted staff interest and pressure to move forward on climate change mitigation and sustainability projects within the organisation, one stating that their Operations and Retail departments had started their own sustainability groups and initiatives. This was seen as connected to the aforementioned wider public awareness: "the 'Blue Planet effect' after the Attenborough 
documentary, that was definitely something that we could see here because, after that, staff were a lot more interested in what we were doing, and I think just questioning things a lot more".

\subsubsection{Recovery}

Recovery was not identified as an a priori theme but emerged as one that occurred as a factor influencing strategy, barriers and opportunities. Within recovery, topics emerged around: calls to secure the benefits of aviation; concerns over public perception of aviation; the role of government in recovery; the role of vaccines and testing in recovery; uncertainty and complexity of recovery; and collaboration as a key element of recovery.

For UK AOs in particular, messaging around protecting the benefits of aviation was deeply tied to concern over how the sector is currently perceived by the UK public, and moreover, to the lack of government support for the sector and perceived failure to retain consumer confidence in air travel. This frustration was seemingly rooted in an underappreciation of the efforts of airports to tackle emissions across all scopes: "I think we're kind of being seen just now as the bad guy in all of this".

The role of government in supporting or enabling the sector's decarbonisation efforts through recovery was discussed by eight AOs. The role of government in supporting Sustainable Aviation Fuels (SAF) supply and demand was noted by two AOs, one alluding to positive recent moves within UK and European Union (EU) Governance in support for SAF. Mandate was seen at the most appropriate government measure that could be implemented, with one $\mathrm{AO}$ referencing the Nordic countries as an exemplar of mandating SAF: "We need government policies to help scale up the market. We need supply side mandates, well designed. We need demand-side incentives to help lower the price".

Uncertainty around the timescales and complex nature of recovery were raised by six AOs in relation to how it could impact their climate change mitigation plans. Uncertainties included: longevity of government-imposed restrictions; future demand and changes in types of travel; uncertain future of some airport stakeholders such as ground handlers. The importance of certainty to the prosperity of aviation was articulated by one AO thus: "As an industry we were predicated on certainty, you know certainty of slots, certainty of schedules, certainty of when passengers would arrive. It's how we make our business work. And that planning element is the reason why airports have been able to be quite successful in growing and growing demand alongside the airlines".

When questioned on how airports could be more resilient to such pressures in the future, three AOs spoke to the importance of multi-stakeholder collaboration. This was seen as a means to prosper as a sector, to unlock win-win solutions between organisations, and was also tied to responsibility for decarbonisation not being burdened on airports alone. The following three responses all carry a similar message in this regard:

- "Cooperation with partners: because the airport itself is not enough to reduce the $\mathrm{CO}_{2}$ emissions and so on efficiently. Cooperation with the airport partners, with the government, with the stakeholders, with the residents and so on ..."

- "Effective collaboration between all the stakeholders. We need to be very, very close-airport, airlines, handling managers, because I think that this is going to be the key, we need to be all in the same team, but for that it is really important to increase our business in the future".

- "The key thing is having that partnership approach-it's not just the airport that's going to fix the problem, it's not just airlines, but how can everybody work together? How can everybody see how they can each understand their contribution and work towards a common goal?"

\section{Discussion}

Impacts.

The predominant view from sustainability managers at AOs is that climate change mitigation interventions and projects will be delayed by COVID-19 but not abandoned, as might sometimes be assumed in times of crisis [10]. Given stakeholder demands, AO participants were fully cognizant of the need to maintain and accelerate, not slow down, climate change action, as hypothecated for other sectors [11]. Most AOs in our 
study anticipated a short-term impact on the implementation of climate change mitigation interventions at airports due to the immediate disruption from pandemic measures to their principal revenue streams (aeronautical and non-aeronautical) leading, in turn, to a concentration on business survival with delayed capital programmes and attempts to reduce costs-as hypothecated [12]. Hub airports with a large domestic share of the market appear more resilient to the impacts of COVID-19, with domestic traffic likely to continue to offer resilience if long-haul routes recover slowly as suggested [13].

Despite the severe and persistent stress of COVID-19 on aviation, the evidence gathered here suggests that climate change retains its position as a strategic priority for airports, with AOs demonstrating commitment to decarbonising the sector. A notably different response compared to previous crises, this reflects an economy-wide recognition of the need to utilize this time of disruption as an opportunity to "build back better". In some cases, climate change has gained increased importance as COVID-19 acts to demonstrate how the impact of a realised external risk can impact the organisation. When comparing the perception of risk from both COVID-19 and climate change, it is understandable that COVID-19 was seen as the highest immediate threat, given its rapid-onset and highly visible ongoing impacts, whereas climate change is perceived as a longer-term albeit highly significant challenge.

Further impacts on emissions and sustainability resulting from COVID-19 were reported. Virus management measures (e.g., disposable PPE) have had a substantial impact on waste streams, as was a reported increase in single-occupancy use of operational vehicles. It is important that gains made in emission mitigation and sustainability over recent years are not permanently undone through longer-term COVID-related shifts in behaviour. Changes such as those reported would become highly problematic in terms of waste volumes and emissions should they persist as passenger numbers return to pre-COVID levels. Whilst a safe and secure air transport system is clearly the priority, pragmatic solutions will be required to mitigate these issues as passenger numbers return. While low- and zero-emission solutions to operational vehicles are being developed and pursued, the use of masks could become a "new normal", suggesting that innovation is also needed to reduce and manage this waste stream. Surprisingly, no measures were reported as being in place to mitigate these impacts, although many of the drivers are beyond the direct control of the airport, emphasising a need for collaboration between all airport stakeholders, a point widely noted by AOs.

The current COVID-19 crisis has made it clear that better approaches should now be adopted to address previously underplayed sustainability issues. This recognition was evident from AOs noting the need to provide healthy buildings and prioritise passenger and colleague health, and is also reflected in the literature [14]. Epidemic management measures at airports have been called for previously [15] and are now likely to become a routine part of planning and decision making in airports. This pandemic has served as a salutary reminder that sustainability issues are multi-dimensional and need to remain in focus even when responding to particular key issues and targets such as climate change and achieving Net Zero.

\section{Interventions and the Net Zero transition.}

Greer, Rakas and Horvath (2020) [16] recommended six impactful practices for airports that can be implemented in the short-term with minimal disruption. These include: renewable electricity (on-site or local); electrification of vehicle fleet; and electrification of gate and GSE. The AOs in our research report having already deployed many of these interventions, e.g., Fixed Electric Ground Power (FEGP) was already implemented by $65 \%$ of the AOs. Furthermore, $86 \%$ intend to pursue on-site renewables in the next 10 years, with the majority already purchasing renewable electricity. Additionally, $68 \%$ of the AOs in the present work have already deployed electric vehicles or intend to do so in the next decade, with no participants reporting that they would not pursue this action.

A somewhat surprising finding was the fact that AOs stated that they do not intend to deploy engineered carbon removal interventions in the next decade. Arguably, smaller 
airports have limited need, or capacity, to employ these measures, but these technologies do feature as part of recognised decarbonisation pathways [17]. After carbon reduction is pushed to its limits within the sector, residual emissions removal will be required to achieve "net-zero". Rather than being reflective of the sector's lack of awareness or desire to act on removals, this finding may be the result of policy uncertainty, disrupting potential progress. What role airports intend and need to play in removals, including intended reliance on out-of-sector removals or removals credits, remains to be seen and requires further study. From the study findings, engineered removals certainly feature as a post-2030 intervention, perhaps linking to perceptions of Green Hydrogen and Synfuel production and use in the aviation sector. In the next 10 years, Nature-Based Solutions, are evidently seen by AOs as a more immediate intervention, although they diminish in favour of engineered removals in the 2030s-this may speak to a recognition that out of sector removals cannot be relied on indefinitely.

Interestingly, $66 \%$ of the AOs envisioned their climate change interventions being implemented within the next decade with these being funded principally from internal sources. This finding should be considered against the longer-term climate goals of the sector: there are questions around how realistic this aim is for the next decade, particularly given the potential for a slow recovery over the coming years [1]. If relatively near-term interventions are delayed significantly, decarbonisation paths to "net-zero" become more challenging and arguably less achievable. However, the majority of AOs clearly expressed that they felt there to be no likely impact on longer-term goals (i.e., Net Zero by 2050), and were confident in a recovery and/or felt sufficient time remained to attain the goals, even if some delay occurs in the short-term.

Solutions to barriers and opportunities were reported. Due to lack of internal funding, EC funding for airports was seen as a particular opportunity for European AOs to maintain momentum with their strategies. In creating spaces for innovation development, such big-budget projects can be likened to "Strategic Niche Management" [18]. The EC funding model is an example of government structure supporting diffusion of innovations at airports and could be replicated by national governments outside the EU to prevent a slow-down on the greening of airports. Additionally, compared to airports independently supporting niche-innovations, they arguably lessen the risks from innovation failure and requirement to subsidise innovation in the current financial environment. In the UK, early calls for fiscal recovery packages in support of climate progress [19] and government investment toward the Net Zero transition has been declared with implications for aviation [20]. For the USA, there has been a recent political shift towards supporting a sustainable transition on a national level which may prove beneficial to the Net Zero agenda. Nonetheless some States are already independently pushing this as recognised by AOs.

Conscious of letting momentum slip, sustainability managers noted a change in attitude toward partnership approaches with several having started exploring alternative financing opportunities. Here, "servicisation", or the offering of land, facilities and resources to innovation partners to fund intervention implementation, may offer significant possibility to progress while access to internal capital is difficult. This could bring opportunities for innovators in areas such as renewable energy, electric vehicles and charging infrastructure, and solutions to decarbonise airport infrastructure. However, as these are potential long-term commitments, care will be needed to avoid unintended consequences or forms of lock-in. COVID-19 presents an obvious challenge but, as noted by [21] (p. 29), such challenges are also often "windows of opportunity" for beneficial change and innovation. Which innovations may break through in this period remains to be seen: in terms of climate change mitigation, AOs are still seeking the same technological solutions as they were pre-COVID. However, a potential acceleration in digitalisation of operations at airports for efficiency and cost reduction is evident from the literature [12,22]. AOs will need to consider how this transition may also play into the benefit of decarbonisation efforts.

Beyond financial and technological opportunities, this study has also revealed evidence of changes in practice that would be of benefit if sustained going forward. These 
are noticeably tied to a change in the usual fast pace of airport operations and include: time to forensically analyse and optimise building management systems, time to explore sustainability methodologies that will benefit capital projects, airport stakeholders having more time to participate, and finally, more opportunity for and less push back against demonstrator-type and other testing opportunities due to high-pressure, dominant operational commitments. Sustainability managers should, therefore, seek to focus efforts in this period of disruption to explore and embed new practices and stakeholder relationships, so they are normalised in a post-COVID airport.

\section{Recovery or Transformation?}

COVID-19 has demonstrated the impact of a global-scale risk, exposing the vulnerability of the aviation system in its current form. In this way, it is a warning and, given the potential for climate change to cause even greater impact on the global aviation system, speaks to the inadvisability of simply returning back to the system in its pre-COVID state.

AOs highlighted that the industry is one predicated on certainty and highlighted the disorder created by the uncertainty around recovery. Some have noted that to counter this, aviation managers should "embrace uncertainty" into long-term decision making [23]. However, perhaps a new certainty can be found in a unified effort to fundamentally pivot the sector, with industry practitioners taking the lead to enact radical changes to accelerate the transition to a sustainable, zero-carbon air transport system. Many of the AOs in this study offered statements that suggest this is something under serious consideration.

This fundamental transition is technologically in sight and arguably inevitable should public opinion continue to mount pressure on the industry. The development of alternative propulsion systems has progressed rapidly, particularly for hydrogen (which has previously suffered hype-disappointment cycles), with commitments for entry into service in the early 2030s [24]. The call for action on climate change is arguably stronger than ever before [25]; consequently, the criticisms of aviation in its current form will continue unless the sector can demonstrate it is fundamentally and rapidly transforming and not returning to where it was pre-COVID. Studying typical patterns in the greening of industries, it can be observed that organisations often change their core business model and values as a result of public opinion forcing consumer behaviour change, supported by stringent policies [26]. However, these external forces are unpredictable and could have a positive or negative influence. Rather than being at risk to changes in public opinion and government policy, the sector should seize the opportunity to take a proactive lead-to demonstrate and communicate what is possible, utilising existing expertise and emerging technologies, thus helping to inform public opinion and policy, and steer the transition to a "built-better", Net Zero aviation system. Positives steps in consumer pro-environmental behaviour need not be in contradiction to aviation if this transition leads to new, sustainable models such as zero-carbon short-haul travel.

For airports to enact this transition to zero-carbon aviation alone is an impossible task, particularly given the financial pressure and resource constraints that look set to continue in 2021. To support the short-term climate responses of AOs, innovative solutions should be welcomed, and new partnerships may enable progress. In addition, the common calls by AOs in the present work for collaboration between all aviation stakeholders should be supported by a unified, coordinated action for Net Zero aviation-something which is as-yet lacking from the supranational bodies that could champion this. With one $\mathrm{AO}$ highlighting the potential variance in participants understanding of the term "Net Zero" and the emission sources they consider "in scope" for achieving it, arguably this should commence with consensus on a robust definition of Net Zero in relation to aviation and airports.

Beyond the above, policy makers must enable this transition for aviation and the pillar industries that will support it. This will require going beyond a sole focus on SAF, to stimulate the emergence of zero-carbon flight through continued investment in R\&D. Political intent to support decarbonisation and sustainable transition has grown over recent years, particularly in the UK and Europe, and appears to be re-emerging in the USA; 
however, with the UNFCCC Conference of the Parties (COP26) approaching, the stage is ready for governments to lay out how they intend to act to enable these changes.

\section{Conclusions}

This research was conducted to explore via questionnaires and semi-structured interviews what impacts the COVID-19 pandemic has had on the progress that AOs have been making, are making and plan to make to address climate change, GHG emissions and other sustainability issues. Given the lack of literature on this topic to date, the present study contributes to the knowledge of how airports have reacted to the external pressure of COVID-19 in terms of their decarbonisation agenda. The conclusions of the study are:

COVID-19 has caused immediate delay to the progress of climate change mitigation interventions and projects at airports, principally as a result of financial constraints linked to decreased passenger numbers. These delays are considered to be short term in their effects.

- The majority of AOs perceived that COVID-19 would have a negligible impact on the long-term decarbonisation goals of airports.

- Climate change has retained its position as a strategic priority, something it had attained pre-COVID-19.

- AOs have already implemented several climate change mitigation interventions and show intention to continue with their strategies. Given the current and persistent strain on capital and resources, implementation plans for the next decade are ambitious.

- The most popular interventions for deployment in the next decade are on-site renewables, EVs and related infrastructure. Engineered carbon removal interventions were recorded as being the most unlikely types to be deployed in this timeframe. This has potential implications for Net Zero because decarbonisation pathways are likely to rely at least to some degree on such interventions to achieve "zero".

- AOs should nurture collaborative approaches with other aviation stakeholders and explore partnership opportunities to implement new business models and more ambitious interventions for climate change, including those that enable and support alternative propulsion aircraft.

Despite the impacts of COVID-19 on aviation and airports, now is an opportune time for AOs to radically pivot to sustainable aviation. Failure to do so will expose the sector to further, greater risks from external forces. This transition is achievable, but Governments need to provide the supporting policy and funding to nurture the development of a sustainable, resilient, low-carbon, aviation system rather than focusing on a return to business-as-usual. Practitioners in the sector are best placed to take a lead and utilise existing expertise and insights to steer it in line with "build back better" and Net Zero and, in doing so, can help to inform policy and public opinion.

Supplementary Materials: The following are available online at https://www.mdpi.com/article/10 .3390/su132112235/s1. Supplementary Material S1: Literature Review. Supplementary Material S2: Table S1. Opportunities identified for emissions reduction-results from questionnaire. Table S2. Barrier to implementation identified-results from questionnaire. Figure S1 (a). Interventions planned 2020 to 2030. Length of bar indicates number of responses. (b). Interventions planned 2030 onward. Length of bar indicates number of responses. (c). Responses for "We already do this". Length of bar indicates number of responses. (d). Responses for "We don't intend to pursue this". Length of bar indicates number of responses.

Author Contributions: Conceptualisation, P.H.; methodology, P.H., R.J.M.; validation, P.H.; formal analysis, P.H.; investigation, P.H.; data curation, P.H.; writing-original draft preparation, P.H.; writing-review and editing, P.H., M.M., R.J.M., M.P.; visualisation, P.H., M.M., R.J.M., M.P.; supervision, M.M., R.J.M., M.P.; project administration, P.H. All authors have read and agreed to the published version of the manuscript.

Funding: This research did not receive any specific grant from funding agencies in the public, commercial, or not-for-profit sectors. Financial support by Heathrow Airport Ltd. is gratefully acknowledged as part of the first author's Practitioner Doctorate in Sustainability Ph.D. in the Centre 
for Environment and Sustainability and the Department of Civil and Environmental Engineering, University of Surrey, UK.

Institutional Review Board Statement: The study was conducted according to the guidelines of the Declaration of Helsinki, and approved by the Institutional Review Board (or Ethics Committee) of University of Surrey (Ref. No.: 640816-640807-65708080, date of approval: 28 September 2020). Due to the nature of the study, no in-depth ethical review by an external committee was required.

Informed Consent Statement: Informed consent was obtained from all subjects involved in the study.

Data Availability Statement: The data presented in this study are not publicly available due to privacy or ethical reasons.

Conflicts of Interest: The authors declare no conflict of interest.

\section{Appendix A}

Table A1. Themes identified by the participants in the semi-structured interviews with Aos.

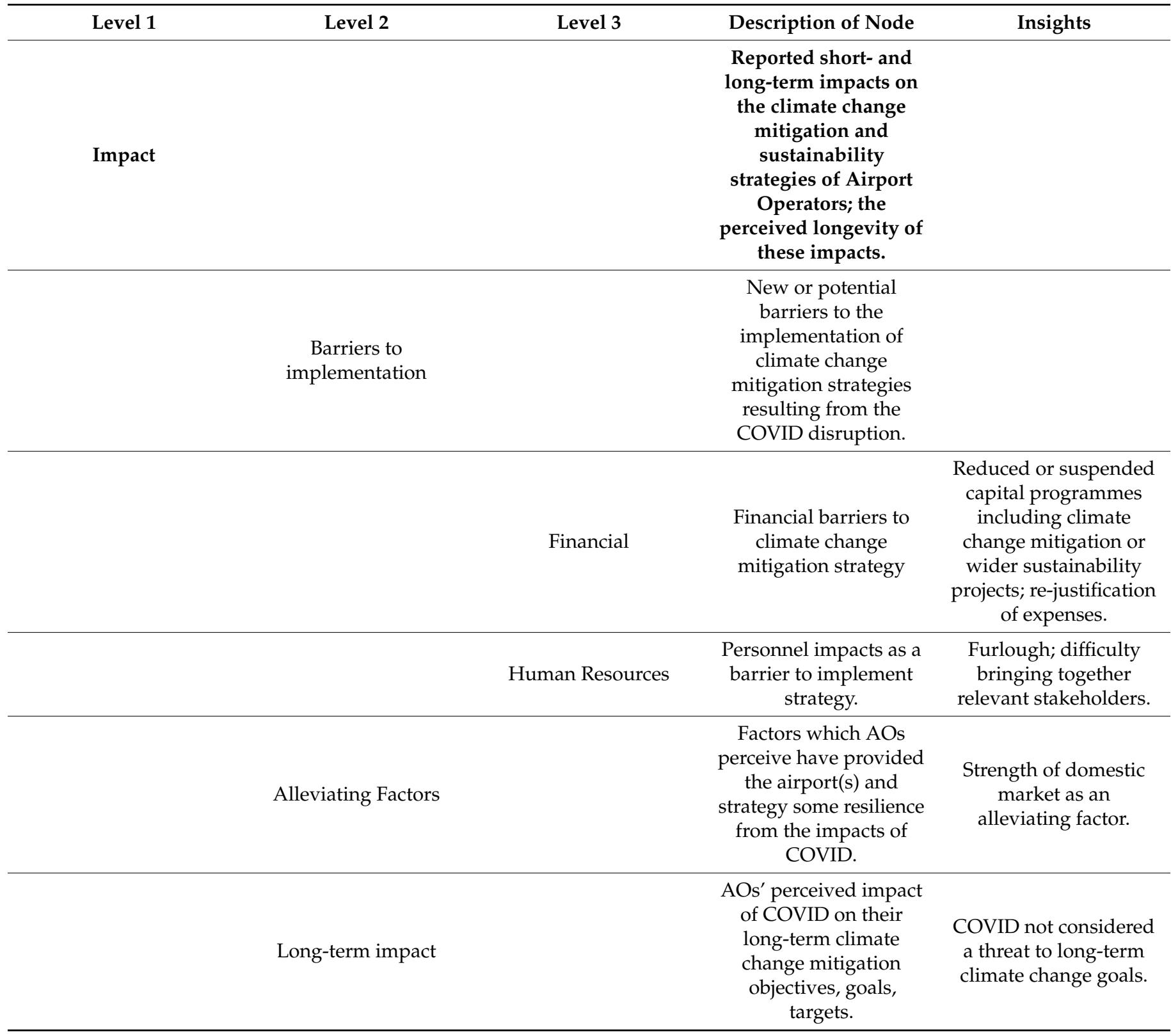


Table 1. Cont.

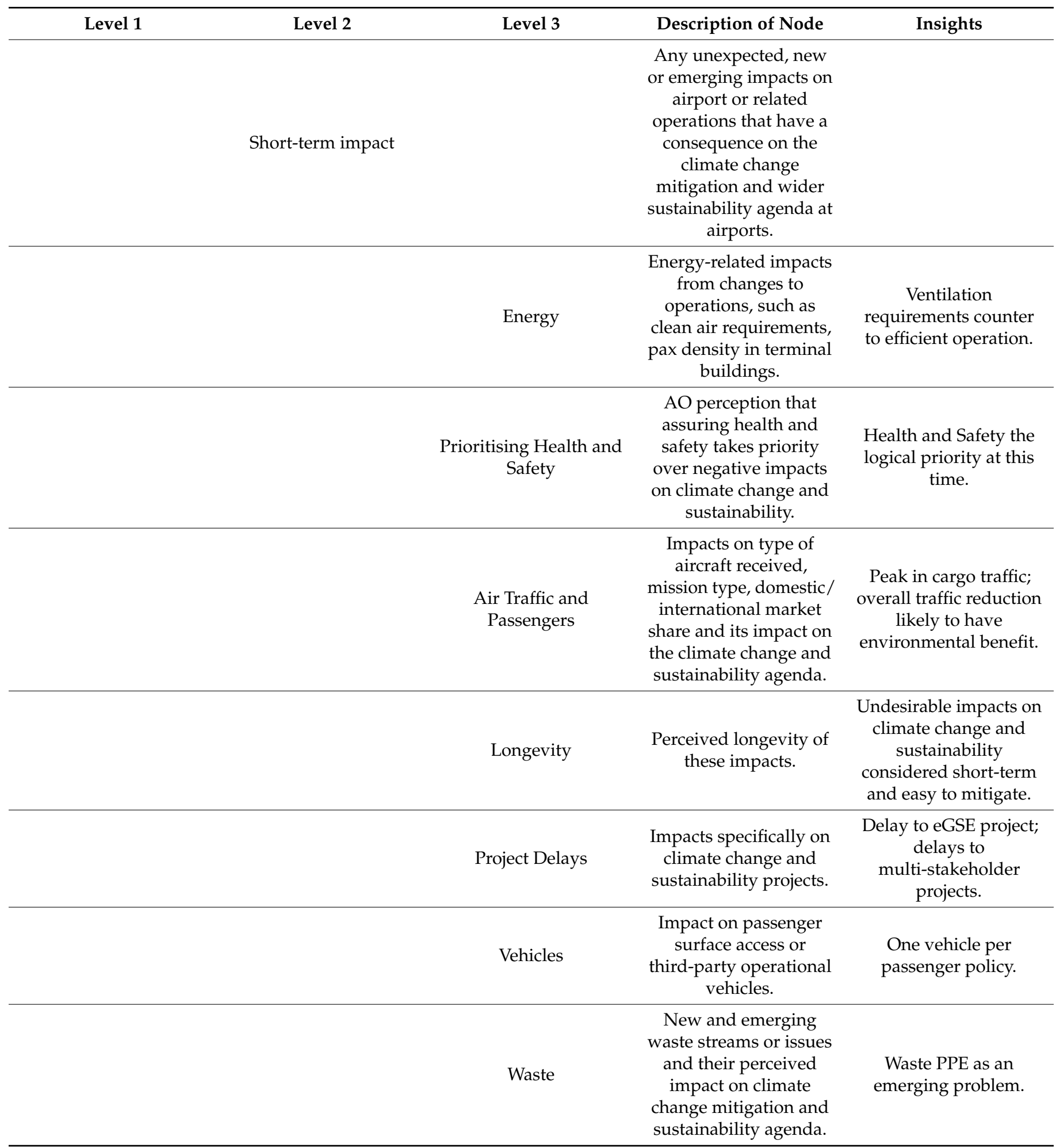


Table 1. Cont.

\begin{tabular}{|c|c|c|c|c|}
\hline Level 1 & Level 2 & Level 3 & Description of Node & Insights \\
\hline \multirow[t]{2}{*}{ Opportunities } & & & $\begin{array}{l}\text { Any new, emerging or } \\
\text { potential } \\
\text { opportunities that } \\
\text { AOs have identified in } \\
\text { this period as } \\
\text { supportive to the } \\
\text { climate change } \\
\text { mitigation or } \\
\text { sustainability agenda } \\
\text { at airports. }\end{array}$ & \\
\hline & $\begin{array}{l}\text { Alternative Funding } \\
\text { and Business Models }\end{array}$ & & $\begin{array}{l}\text { Innovation; potential } \\
\text { new methods of } \\
\text { financing projects; } \\
\text { potential new business } \\
\text { models. }\end{array}$ & $\begin{array}{l}\text { Exploration of green } \\
\text { financing and } \\
\text { partnership models for } \\
\text { on-site renewables and } \\
\text { EV charging } \\
\text { infrastructure. }\end{array}$ \\
\hline
\end{tabular}

New methods of

working that are beneficial to the climate change and

Teleworking; new spirit

Methods of Working

Pace sustainability agenda; new opportunities for airport stakeholder collaboration.

A slower pace of working unlocking new opportunities.

This period as a time to review, reassess and reprioritise strategy

ritisation an and interventions.

Time for consideration of new sustainability methods; easier to implement pilots.

Strategic review; focus on delivery of highest carbon benefit for investment.

\section{AOs' comments on recovery in relation to the climate change and sustainability \\ agenda at airports-an integral theme undercutting many responses impacting barriers, opportunities and strategy.}

Recovery
$\mathrm{AO}$ comments on the need to protect

Benefits and public perception

aviation's benefits; AOs concern over public perception of aviation during this period.
Calls to protect the benefits of aviation; impact on consumer confidence. 
Table 1. Cont.

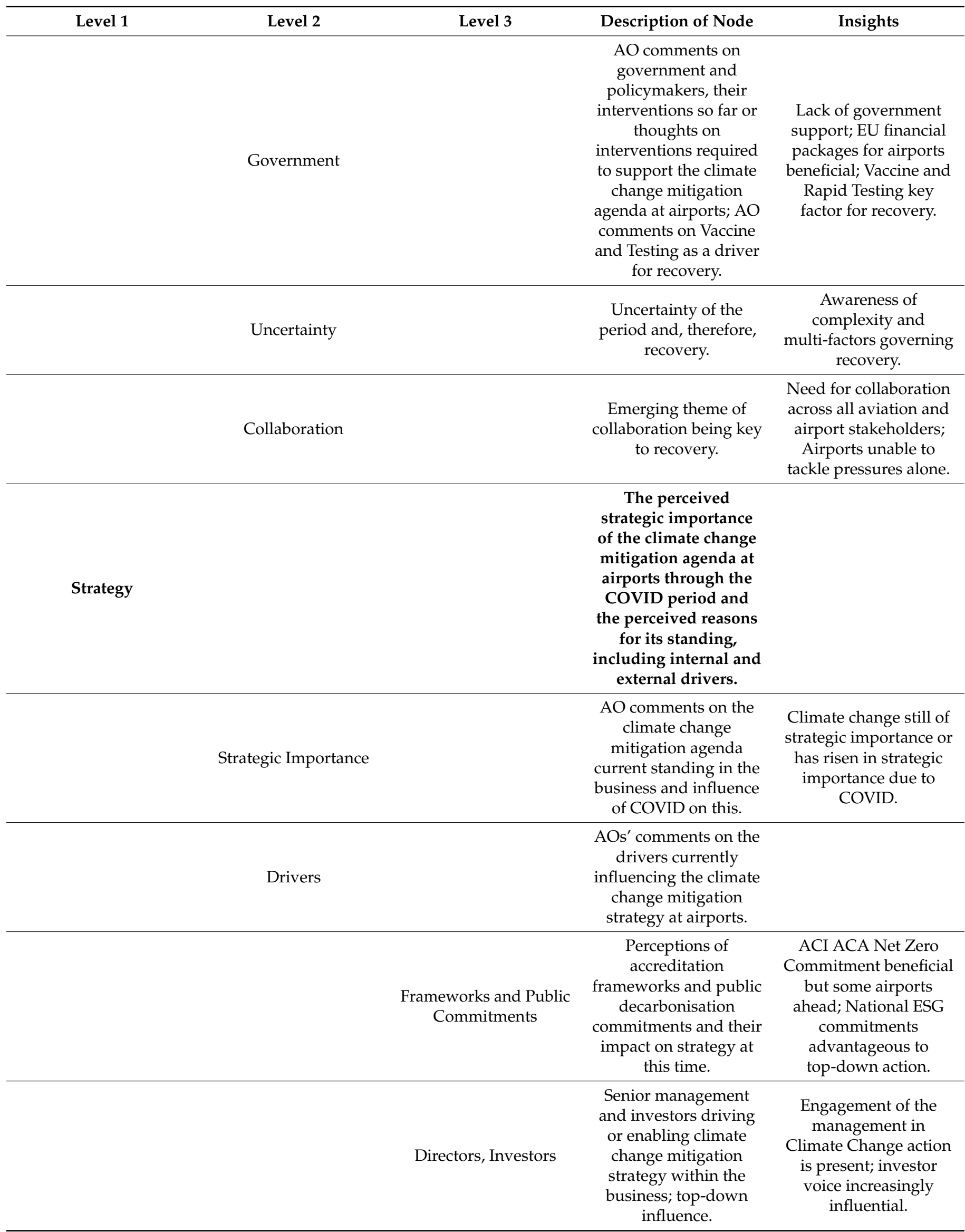


Table 1. Cont.

\begin{tabular}{|c|c|c|c|c|}
\hline Level 1 & Level 2 & Level 3 & Description of Node & Insights \\
\hline & & Public & $\begin{array}{l}\text { Public pressure } \\
\text { influencing the agenda. }\end{array}$ & $\begin{array}{l}\text { Increasing public } \\
\text { understanding and } \\
\text { pressure }\end{array}$ \\
\hline & & Staff & $\begin{array}{l}\text { AO comments on } \\
\text { colleagues within the } \\
\text { business push the } \\
\text { agenda; bottom-up. }\end{array}$ & $\begin{array}{l}\text { Colleagues creating } \\
\text { their own sustainability } \\
\text { groups. }\end{array}$ \\
\hline
\end{tabular}

\section{References}

1. Air Transport Bureau. Effects of Novel Coronavirus (COVID-19) on Civil Aviation: Economic Impact Analysis; International Civil Aviation Organization (ICAO): Montréal, QC, Canada, 2021.

2. Oneworld. Oneworld Member Airlines Commit to Net Zero Carbon Emissions. 2020. Available online: https://www.oneworld. com/news/2020-09-11-oneworld-member-airlines-commit-to-net-zero-carbon-emissions-by-2050 (accessed on 1 May 2021).

3. United Nations DGC. Climate Change and COVID-19: UN Urges Nations to 'Recover Better'. 2020. Available online: https:/ / www.un.org/en/un-coronavirus-communications-team/un-urges-countries- $\backslash \mathrm{T} 1 \backslash$ textquoteleftbuild-back-better $\backslash \mathrm{T} 1$ $\backslash$ textquoteright (accessed on 1 May 2021).

4. Looi, M.K. Covid-19: Is a second wave hitting Europe? BMJ 2020, 371, m4113. [CrossRef] [PubMed]

5. Ranganathan, J.; Corbier, L.; Schmitz, S.; Oren, K.; Dawson, B.; Spannagle, M.; Bp, M.M.; Boileau, P.; Canada, E.; Frederick, R.; et al. The Greenhouse Gas Protocol: A Corporate Accounting and Reporting Standard. 2015. Available online: https: //ghgprotocol.org/sites/default/files/standards/ghg-protocol-revised.pdf (accessed on 3 May 2021).

6. King, N.; Brooks, J. Thematic Analysis in Organisational Research. In The SAGE Handbook of Qualitative Business and Management Research Methods: Methods and Challenges; SAGE Publications Ltd.: London, UK, 2018; pp. 219-236. [CrossRef]

7. King, N.; Brooks, J.M. Template Analysis for Business and Management Students, Template Analysis for Business and Management Students; SAGE Publications Ltd.: London, UK, 2017. [CrossRef]

8. ACI. ACI Reveals Top 20 Airports for Passenger Traffic, Cargo, and Aircraft Movements. 2020. Available online: https: / /aci.aero/news/2020/05/19/aci-reveals-top-20-airports-for-passenger-traffic-cargo-and-aircraft-movements/ (accessed on 10 December 2020).

9. Eurostat. AVIA_PAOA: Air Passenger Transport by Main Airports in Each Reporting Country. Eur. Comm. Eurostat Databrowser. 2021. Available online: https:/ / ec.europa.eu/eurostat/databrowser/view/avia_paoa/default/table?lang=en (accessed on 1 May 2021).

10. Amankwah-Amoah, J. Stepping up and stepping out of COVID-19: New challenges for environmental sustainability policies in the global airline industry. J. Clean. Prod. 2020, 271, 123000. [CrossRef] [PubMed]

11. Jones, P.; Comfort, D. A commentary on the COVID-19 crisis, sustainability and the service industries. J. Public Aff. 2020, 20. [CrossRef]

12. Serrano, F.; Kazda, A. The future of airports post COVID-19. J. Air Transp. Manag. 2020, 89, 101900. [CrossRef]

13. Suau-Sanchez, P.; Voltes-Dorta, A.; Cugueró-Escofet, N. An early assessment of the impact of COVID-19 on air transport: Just another crisis or the end of aviation as we know it? J. Transp. Geogr. 2020, 86, 102749. [CrossRef]

14. Barreiro-Gen, M.; Lozano, R.; Zafar, A. Changes in Sustainability Priorities in Organisations due to the COVID-19 Outbreak: Averting Environmental Rebound Effects on Society. Sustainability 2020, 12, 5031. [CrossRef]

15. Chung, L.H. Impact of pandemic control over airport economics: Reconciling public health with airport business through a streamlined approach in pandemic control. J. Air Transp. Manag. 2015, 44-45, 42-53. [CrossRef] [PubMed]

16. Greer, F.; Rakas, J.; Horvath, A. Airports and environmental sustainability: A comprehensive review. Environ. Res. Lett. 2020, 15, 103007. [CrossRef]

17. Climate Change Committee, 2020. The Sixth Carbon Budget: The UK's Path to Net Zero. Available online: https://www.theccc. org.uk/publication/sixth-carbon-budget/ (accessed on 3 May 2021).

18. Kemp, R.; Schot, J.; Hoogma, R. Regime shifts to sustainability through processes of niche formation: The approach of strategic niche management. Technol. Anal. Strateg. Manag. 1998, 10, 175-198. [CrossRef]

19. Hepburn, C.; O'callaghan, B.; Stern, N.; Stiglitz, J.; Zenghelis, D. Will COVID-19 fiscal recovery packages accelerate or retard progress on climate change? Oxf. Smith Sch. Enterp. Environ. 2020, 36, S359-S381. [CrossRef]

20. HM Government. The Ten Point Plan for a Green Industrial Revolution. 2020. Available online: https://www.gov.uk/ government/publications/the-ten-point-plan-for-a-green-industrial-revolution (accessed on 3 May 2021).

21. Geels, F.W. The multi-level perspective on sustainability transitions: Responses to seven criticisms. Environ. Innov. Soc. Transit. 2011, 1, 24-40. [CrossRef] 
22. Drljača, M.; Štimac, I.; Bračić, M.; Petar, S. The Role and Influence of Industry 4.0. in Airport Operations in the Context of COVID-19. Sustainability 2020, 12, 10614. [CrossRef]

23. Linden, E. Pandemics and environmental shocks: What aviation managers should learn from COVID-19 for long-term planning. J. Air Transp. Manag. 2021, 90, 101944. [CrossRef]

24. Vittadini, G. Novel Aircraft Technological Concepts, in: ICAO Stocktaking. 2020. p. 4. Available online: https://www.icao.int/ Meetings/Stocktaking2020/Pages/default.aspx (accessed on 11 September 2020).

25. UNDP and University of Oxford. Peoples' Climate Vote: Results. 2021. Available online: https://www.undp.org/publications/ peoples-climate-vote (accessed on 3 May 2021).

26. Penna, C.C.R.; Geels, F.W. Multi-dimensional struggles in the greening of industry: A dialectic issue lifecycle model and case study. Technol. Forecast. Soc. Chang. 2012, 79, 999-1020. [CrossRef] 